\title{
EXPERIMENTAL INFECTION OF THE UPPER GENITAL TRACT OF FEMALE GRIVET MONKEYS WITH MYCOPLASMA FERMENTANS
}

\author{
B. R. Møller, E. A. Freundt, F. T. Black, and F. Melsen \\ Institute of Medical Microbiology and Institute of Pathology, University of Aarhus, \\ DK-8000 Aarhus C, Denmark \\ Plates VI-VII
}

MYCOPLASMA FERMENTANS represents $2 \%$ or less of the mycoplasma flora of the lower urogenital tract of man (Black and Rasmussen, 1968; Mårdh, Nilsson and Bjelle, 1973). It has been isolated on one occasion from an inflamed uterine tube (Freundt, 1953), but the possible significance of this species as an aetiological agent in gynaecological inflammatory disease requires further study. The very frequent association of $M$. fermentans with rheumatoid arthritis reported by Williams, Brostoff and Roitt (1970) remains largely unconfirmed, although the organism has been isolated from the synovial fluid of patients with rheumatoid and non-rheumatoid arthritis (Mårdh $e t$ al., 1973). The toxic effect of $M$. fermentans membrane fractions, when inoculated intraperitoneally in high concentrations into mice (Gabridge and Murphy, 1971; Gabridge, Yip and Hedges, 1975), provides another impetus for studying the potential pathogencity of this organism.

In an earlier study, female grivet monkeys proved suitable as an experimental model for infection with Mycoplasma hominis (Møller et al., 1978; Møller and Freundt, 1979). The present paper describes the experimental production of salpingitis and parametritis by M.fermentans in grivet monkeys, by the same techniques.

\section{MATERIALS AND METHODS}

M. fermentans. Two strains were used. Strain S38 was isolated in 1953 from the uterine tube of a patient suffering from recurring salpingitis (Freundt, 1953). After primary isolation and a few subsequent culture passages, the strain was stored in the lyophilised state at $4^{\circ} \mathrm{C}$. Upon revival of the lyophil in 1977 , cloning was performed three times and the identity of the strain was confirmed as $M$. fermentans by growth-inhibition and epi-immunofluorescence tests. Strain D1882 was isolated in this laboratory from the cervix of a 15-year-old girl attending a clinic for sexual guidance; it was cloned once. For preparation of inoculum, the organisms were subcultured twice in a liquid B-medium (Freundt, Ernø and Lemcke, 1979); the second subculture, in $300 \mathrm{ml}$ of medium, was harvested, in the late log phase of growth, by centrifugation (10 000 r.p.m. for $20 \mathrm{~min}$.) and the pellet of organisms was resuspended in $5 \mathrm{ml}$ of PBS, $p \mathrm{H} \mathrm{7 \cdot 2.}$ The concentrated suspension contained approximately $10^{8}$ colony-forming units (c.f.u.) per $\mathrm{ml}$. Portions of $1 \mathrm{ml}$ were frozen and stored at $-70^{\circ} \mathrm{C}$, The number of c.f.u. per $\mathrm{ml}$ of the individual lots was redetermined before each experiment. 
Animals. Nine female grivet monkeys, weight $1.5-2.2 \mathrm{~kg}$, were used. They had been imported from East Africa, but before experimental infection they were kept in quarantine for at least 6 weeks and tested for Salmonella and Shigella and by the tuberculin test. During the experiments the animals were caged individually in an isolation room, as described earlier (Møller et al., 1978).

Preinoculation testing. Cultivation experiments were made to exclude spontaneous colonisation of the monkeys, particularly with $M$. hominis, $M$. fermentans, $M$. primatum, and Ureaplasma urealyticum; specimens were taken from the pharynx, urethra, vagina, and rectum. This and other pre-inoculation testings were performed essentially as described by Møller et al. (1978).

Experimental infection. This was attempted by three different routes of inoculation: (A) monkeys I, II, and III were given injections of $0.4 \mathrm{ml}$ of mycoplasma suspension directly into both uterine tubes exposed by laparotomy (Møller et al., 1978), I and II with $M$. fermentans strain S38, and III with strain D1882; (B) monkeys IV and V were given $0.4 \mathrm{ml}$ of the S38 suspension into the uterine cavity, by injection through the cervical canal with a $0.4-\mathrm{mm}$ syringe; the cervix was not dilated; (C) in the case of monkeys VI and VII, the isthmus of the uterine tubes was closed by ligatures at laparotomy and strain S38 was injected into the uterine cavity; this was followed by dilatation of the cervix and curettage of the endometrium, as described in detail previously (Møller and Freundt, 1979).

Controls. Monkey VIII was given an injection of PBS directly into the lumen of the uterine tubes at laparotomy, and monkey IX was treated like monkeys VI and VII except that PBS was injected instead of mycoplasmas.

For all surgical procedures, the monkeys were anaesthetised with phenyclidine hydrochloride (Sernylan, $20 \mathrm{mg} / \mathrm{ml}), 0.15 \mathrm{ml}$; chlorpromazin $(0.25 \%$ solution), $0.5 \mathrm{ml}$; and atropin $(0.1 \%$ solution), $0.2 \mathrm{ml}$.

Assessment of lesions and collection of specimens. All monkeys were laparotomised 5, 10,23, and 40 days postinoculation (p.i.) in order to examine the abdominal sexual organs for gross lesions, and to collect biopsy and swab specimens from the uterus, uterine tubes, fimbriae, parametria, and the intestinal serosa. Swabs were taken from the vagina at intervals from the 5 th day until about 3 months p.i.

Culturing of specimens. Cultivation for $M$. fermentans and bacteria was performed as described for M. hominis. (Møller et al., 1978).

Histology. Tissue biopsies were fixed in $10 \%$ formalin, embedded in paraffin, and stained with haematoxylin and eosin for histological examination.

Serology. Determination of antibodies was carried out by the indirect haemagglutination (IHA) test, with fresh sheep erythrocytes sensitised with the supernatant fluid obtained by centrifugation of sonicated antigen (Krogsgaard-Jensen, 1971).

\section{Results}

None of the seven female grivet monkeys experimentally infected with $M$. fermentans showed any clinical signs of inflammation. Body temperature and leukocyte counts remained normal. The ESR showed a moderate rise when tested on days 5 and 10 p.i.

\section{Gross lesions}

On laparotomy, monkeys I, II, and III, which had been given injections of mycoplasmas directly into the uterine tubes, and monkeys VI and VII, which had received their injections into the uterine cavity itself, followed by curettage, showed obvious signs of inflammation only of the genital organs, at 10 and 23 days p.i. The parametria were moderately swollen and the tubes were slightly 
oedematous and showed moderate hyperaemia. No exudate or cystic structures developed. The uterus and the ovaries were invariably normal.

Monkeys IV and V, which had been given mycoplasma injections into the uterine cavity without curettage, showed no signs of inflammation of the upper genital tract or elsewhere, throughout the observation period.

The control monkeys (VIII and IX) maintained an apparently normal genital tract throughout the experimental period.

The joints of the extremities of the monkeys inoculated with $M$. fermentans were regularly examined for swelling and redness, but with negative results.

\section{Histology}

Monkeys I, II and III and monkeys VI and VII demonstrated pronounced inflammatory lesions in the parametria and in the subserosa of the fallopian tubes. The most notable findings in the parametria were oedema and hyperaemia appearing on day 5 p.i., with infiltration by moderate numbers of lymphocytes and polymorphonuclear granulocytes into the tissues; in some areas there was marked fibroblastic proliferation and necrosis of fatty tissue at 10 and 23 days p.i. (fig. 1). The inflammatory lesions in the fallopian tubes were characterised by moderate infiltration of lymphoid cells into the subserosa, with slight oedema; there was no cellular infiltration of the muscularis layer or of the mucosa, the epithelium was intact and there was no exudate in the lumen. The inflammatory reactions were most pronounced on day 10 p.i. (fig. 2), but by day 23 only slight cellular infiltration remained in the parametria and the uterine tubes were practically normal; by day 40 all signs of inflammation had disappeared.

Monkeys IV and V and monkeys VIII and IX had no or only minimal inflammatory changes, confined to the subserosa of the tubes and parametria.

\section{Isolation of mycoplasmas and bacteria}

$M$. fermentans was recovered from the uterus and the vagina of monkey II, and from the fimbriae of monkey V, on day 5 p.i. but not later. From the other four monkeys infected with $M$. fermentans strain S38, the organism could be recovered only from the vagina on day 5 p.i. Monkey III, inoculated with $M$. fermentans strain D1882, yielded no growth from the internal genital organs; however, vaginal cultures from this monkey were heavily overgrown by bacteria.

Significant bacterial growth was not obtained from the swabs taken from any of the monkeys at laparotomy.

\section{Serology}

None of the monkeys had detectable IHA antibodies to $M$. fermentans in their preinoculation sera. Significant levels of antibody developed in monkeys I, II and III and in monkeys VI and VII during the course of the infection, 


\section{TABLE}

Development of antibody in grivet monkeys infected with $M$. fermentans by various routes of inoculation

\begin{tabular}{|c|c|c|c|c|c|c|c|}
\hline \multirow{2}{*}{$\begin{array}{l}\text { Route of } \\
\text { inoculation }\end{array}$} & \multirow[b]{2}{*}{ Monkey no.* } & \multicolumn{6}{|c|}{$\begin{array}{l}\text { Indirect-haemagglutination (IHA) } \\
\text { antibody titre at intervals (days) after } \\
\text { infection }\end{array}$} \\
\hline & & 0 & 5 & 10 & 23 & 46 & 60 \\
\hline $\begin{array}{l}\text { Directly } \\
\text { into the } \\
\text { uterine tube }\end{array}$ & $\begin{array}{l}\text { I } \\
\text { II } \\
\text { III }\end{array}$ & $\begin{array}{l}\leqslant 20 \\
\leqslant 20 \\
\leqslant 20\end{array}$ & $\begin{array}{l}\leqslant 20 \\
\leqslant 20 \\
\leqslant 20\end{array}$ & $\begin{array}{r}160 \\
160 \\
40\end{array}$ & $\begin{array}{l}40 \\
80 \\
80\end{array}$ & $\begin{array}{r}\leqslant 20 \\
80 \\
\leqslant 20\end{array}$ & $\begin{array}{l}\leqslant 20 \\
\text { ND } \\
\text { ND }\end{array}$ \\
\hline $\begin{array}{l}\text { Into the uterine } \\
\text { cavity without curettage }\end{array}$ & $\begin{array}{l}\text { IV } \\
\text { V }\end{array}$ & $\begin{array}{l}\leqslant 20 \\
\leqslant 20\end{array}$ & $\begin{array}{l}\leqslant 20 \\
\leqslant 20\end{array}$ & $\begin{array}{l}\leqslant 20 \\
\leqslant 20\end{array}$ & $\begin{array}{l}\leqslant 20 \\
\leqslant 20\end{array}$ & $\begin{array}{l}\leqslant 20 \\
\leqslant 20\end{array}$ & $\begin{array}{l}\leqslant 20 \\
\leqslant 20\end{array}$ \\
\hline $\begin{array}{l}\text { Into the uterine } \\
\text { cavity with curettage }\end{array}$ & $\begin{array}{l}\text { V1 } \\
\text { VII }\end{array}$ & $\begin{array}{l}\leqslant 20 \\
\leqslant 20\end{array}$ & $\begin{array}{l}\leqslant 20 \\
\leqslant 20\end{array}$ & $\begin{array}{l}80 \\
80\end{array}$ & $\begin{array}{l}80 \\
80\end{array}$ & $\begin{array}{l}\leqslant 20 \\
\leqslant 20\end{array}$ & $\begin{array}{l}\text { ND } \\
\leqslant 20\end{array}$ \\
\hline Controls & VIII & $\begin{array}{l}\leqslant 20 \\
\leqslant 20\end{array}$ & $\begin{array}{l}\leqslant 20 \\
\leqslant 20\end{array}$ & $\begin{array}{l}\leqslant 20 \\
\leqslant 20\end{array}$ & $\begin{array}{l}\leqslant 20 \\
\leqslant 20\end{array}$ & $\begin{array}{l}\leqslant 20 \\
\leqslant 20\end{array}$ & $\begin{array}{l}\leqslant 20 \\
\leqslant 20\end{array}$ \\
\hline
\end{tabular}

$\mathrm{ND}=$ Not done.

* Monkeys I, II and IV-VII were infected with strain S38, and monkey III with strain D1882; the control monkeys were given only PBS.

reaching maximum titres of $80-160$ (table). There was no detectable antibody to $M$. fermentans in monkeys IV and V, or in the control monkeys, during the observation period (table).

IHA antibodes to $M$. hominis were not detected in any of the monkeys at the start of the experiment and did not appear subsequently.

\section{Discussion}

M. fermentans is a rather uncommon inhabitant of the urogenital tract of man. Thus, Braun et al. (1970) did not isolate it from urine or cervical specimens from any of 568 pregnant women, and Black and Rasmussen (1968) found that only $2 \%$ of Mycoplasma strains isolated from the urethra of 275 men were $M$. fermentans. In a single report, this micro-organism has been isolated in pure culture from the uterine tube of a patient suffering from subacute salpingitis (Freundt, 1953). In the present study, five out of seven monkeys given injections of $M$. fermentans into the genital tract developed, within a few days, acute inflammation of the upper genital tract accompanied by an antibody response. Three of the five had been given their injections directly into the uterine tubes, and the other two into the uterine cavity followed by curettage. On the other hand, two monkeys given their mycoplasma injections into the uterine cavity through the cervical canal, without subsequent curettage, failed to develop any signs of inflammation. The fact that an inflammatory reaction occurred only when injection of the intrauterine cavity was followed by curettage indicates that spread of $M$. fermentans to the parametria and uterine tubes must have taken place through blood vessels and lymphatics. The lesions produced by $M$. fermentans were essentially the same as those observed in experimental $M$. hominis infection, with similar routes of 
inoculation, but the antibody response was generally of shorter duration (Møller et al., 1978; Møller and Freundt, 1979).

The possible association of $M$. fermentans with arthritis received no support from the present study.

Although, to our knowledge, there is only one previous report of a possible association between $M$. fermentans and upper genital-tract infection (Freundt, 1953) our results may provide a stimulus to further clinical investigations in man. Such studies are in progress in our laboratory.

\section{SUMMARY}

Mycoplasma fermentans inoculated directly into the uterine tubes of female grivet monkeys produced a self-limiting acute salpingitis and parametritis. The inflammation was accompanied by a significant rise in the titre of specific indirect haemagglutinating antibodies. Inoculation of $M$. fermentans into the uterine cavity through the cervical canal without dilatation of the cervix produced practically no signs of inflammation and no antibody response. However, when the intrauterine inoculation of mycoplasmas was followed by curettage of the endometrium, in animals whose uterine tubes had been closed by ligatures, pronounced upper genital-tract inflammation developed, together with a significant antibody response.

This work was supported by grants from the Research Foundation of the University of Aarhus (1977-7131/01-5), the Danish Medical Research Council (512-10782), and Aarhus Oliefabrik.

\section{REFERENCES}

BLACK, F. T. AND Rasmussen, O. G. 1968. Occurrence of T-strains and other mycoplasmata in non-gonococcal urethritis. Br. J. vener. Dis., 44, 324.

Braun, P., Klein, J. O., Lee, Y. H. AND Kass, E. H. 1970. Methodologic investigations and prevalence of genital mycoplasmas in pregnancy. J. infect. Dis., 121, 391.

FREUNDT, E. A. 1953. The occurrence of micromyces (pleuropneumonia-like organism) in the female genito-urinary tract. Acta. path. microbiol. scand., 32, 468.

FreUNDT, E. A., ERNø, H. AND LEMCKE, R. 1979 Identification of mycoplasmas, In Methods in microbiology, vol. 13, edited by J.R. Norris and D.W. Ribbons. Academic Press: London and New York, (in press).

GabRIDGE, M. G. AND MURPhY, W. H. 1971. Toxic membrane fractions from Mycoplasma fermentans. Infect. Immun., 4, 678.

GabRIDGE, M. G., YIP, D-M. AND HedGes, K. 1975. Levels of lysosomal enzymes in tissues of mice infected with Mycoplasma fermentans. Infect. Immun., 12, 233.

KROGSGAARD-JENSEN, A. 1971. Indirect hemagglutination with Mycoplasma antigens: effects of $\mathrm{pH}$ on antigen sensitization of tanned fresh and formalinized sheep erythrocytes. Appl. Microbiol., 22, 756.

Møller, B. R. AND FReUndT, E. A. 1979. Experimental infection of the genital tract of female grivet monkeys by Mycoplasma hominis; effects of different routes of infection. Infect. Immun., (in press).

Møller, B. R., Freundt, E. A., Black, F. T. and Frederiksen, P. 1978. Experimental infection of the genital tract of female grivet monkeys by Mycoplasma hominis. Infect. Immun. 20, 248.

MÅRDH, P-A., NiLSSON, F. J. AND BJELLE, A. 1973. Mycoplasmas and bacteria in synovial fluid from patients with arthritis. Ann. rheum. Dis., 32, 319.

Williams, M. H., Brostoff, J. And Roitt, I. M. 1970. Possible role of Mycoplasma fermentans in pathogenesis of rheumatoid arthritis. Lancet, 2, 277. 
MCOPLASMA INFECTION OF MONKEY GENITAL TRACT
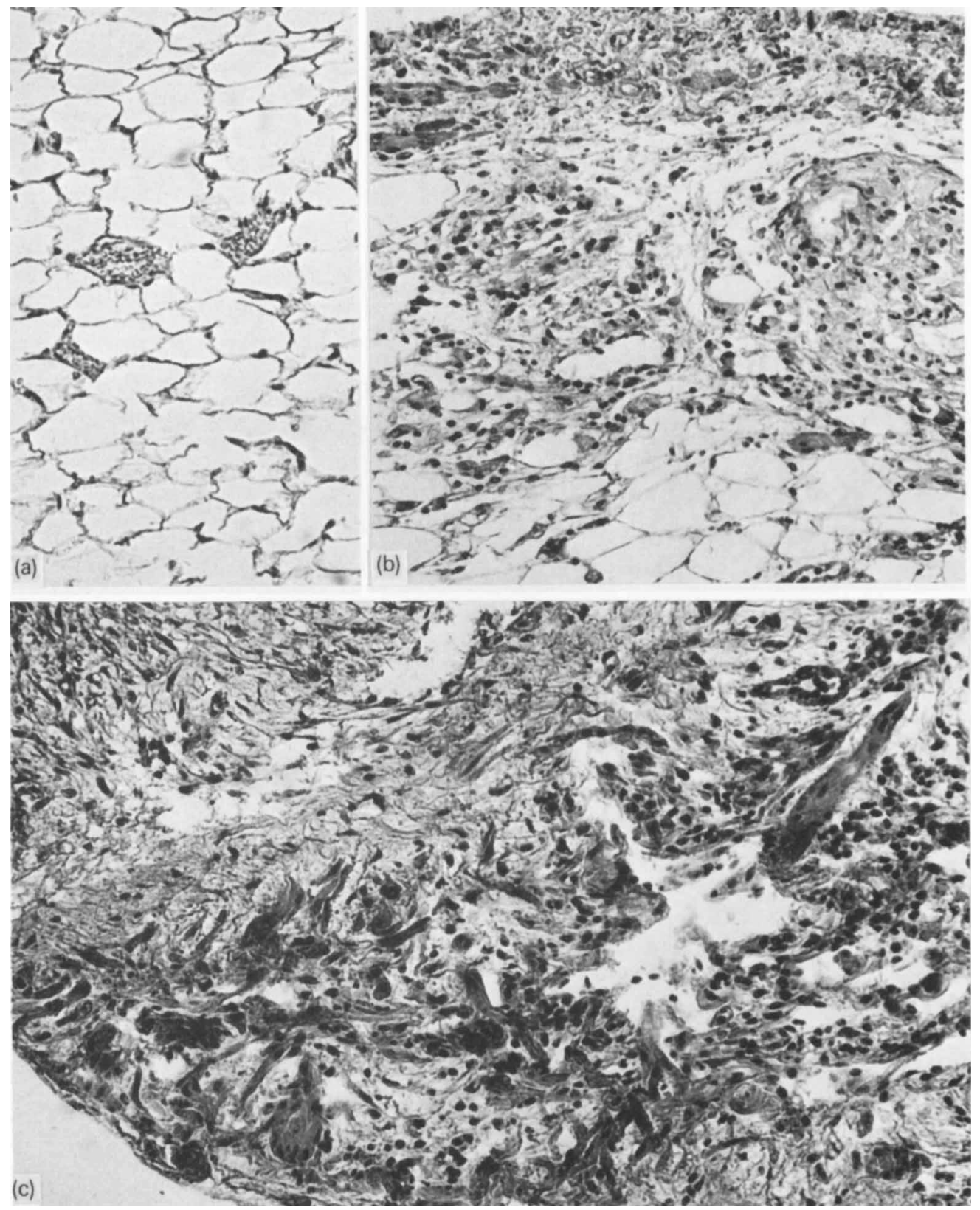

FIG. 1.-Histopathological appearance of the parametrium of monkey no. VI, at intervals after inoculation of $M$. fermentans into the uterine cavity followed by curettage. (A) Day of inoculation, showing normal parametrium. (B) Day 5 p.i., showing marked inflammatory changes. (C) Day 10 p.i., showing marked inflammation, with fibrosis of the tissue. Haematoxylin and eosin (HE). $\times 90$. 


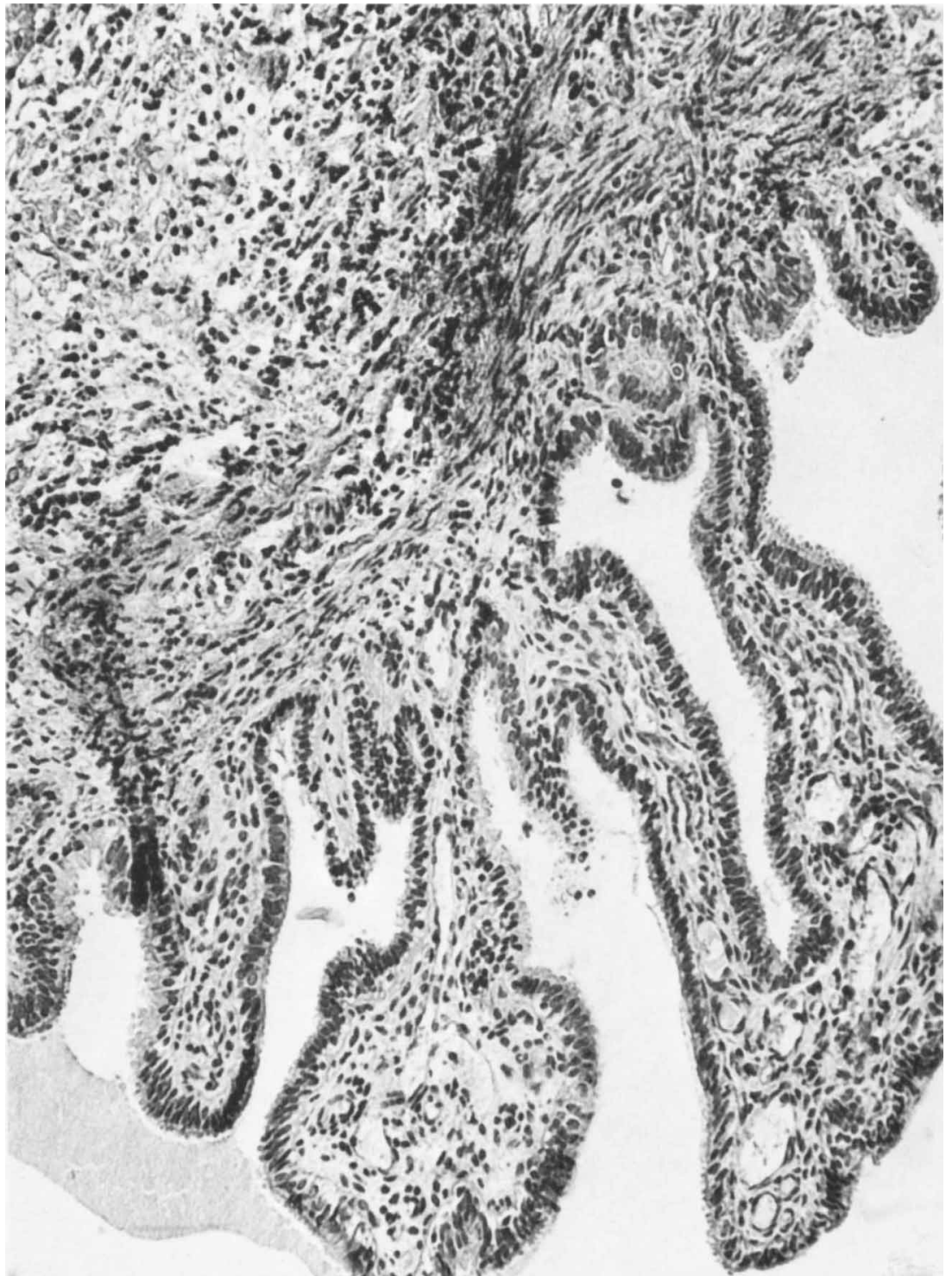

Fig. 2. - Histopathological appearance of the uterine tube of monkey no. VI, 10 days after inoculation of $M$. fermentans into the uterine cavity, showing moderate inflammation of the subserosa; the muscularis layers and the epithelium are normal. HE. $\times 90$. 